the morbidly vascular part-a condition apparently the most trivial and accidental; and yet it returns, with unerring certainty under the like conditions, as our guide to diagnosis. The multiplied generations of the raccine vesicle from one lymph, maintaining to this day, in all respects, the characteristics of that which first arose under the hand of its immortal discoverer, is one of the strongest evidences that I could adduce of such fidelity, and may well encourage us to the investigation of physical signs as an evidence of the pathological causes to which they are due.

But our diagnosis is not always of one morbid state. There may be grafted upon some special diathesis, as of tubercle or of gout, the effects of alcohol, syphilis, mercury, and miasm. No doubt even more complicated instances could be given, but this will suffice to show the character our diagnosis must take before we can proceed to treatment.

As health is our object, or as near an approach to it as circumstances admit, hygiene and therapeutics claim the last and highest place in our thoughts. Happily, at length, hygiene has gained strength enough to maintain an independent vitality as a science. To know and counteract the causes of disease before they become effective is evidently the triumph of our art; but it will be long before mankind will be wise enough to accept the aid we could give them in this direction. Ignorance of the laws of health and intemperance of all kinds are too powerful for us. Still we shall continue to wage against them an undying crusade; and truly we may to-day congratulate ourselves that no crusade ever called forth more able and devoted warriors than are engaged in this.

The diseases of the young are in large part preventable diseases.

Epidemics carry off in great proportion the healthy members of a community.

It is futile, if not worse, to speak as some do of leaving diseases to work out their ends, as agents of a moral police. Medicine allows no such prerogative to our judgment. It is enough for us that diseases prevail, to stimulate our best efforts fur their prevention, without our asking a question beyond.

Nothing can stimulate science more to the investigation of therapeutics than the feeling that the diseases calling for treatment prevail in spite of our best efforts to prevent them. Where hygiene fails, properly commences the work of therapeutics ; but it is painful to find ourselves occupied in making feeble and often useless efforts to combat the effects of a poison which might perhaps have been stamped out in its beginnings.

The strength of modern therapeutics lies in the clearer perception than formerly of the great truth that diseases are but perverted lifeprocesses, and have for their natural history not only a beginning, but equally a period of culmination and decline.

In common inflammatory affections, this is now admitted to be the all but universal law. By time and rest, that innate vis madicatrix, "Which hath an operation more divine

Than breath or pen can give expressure to,"

reduces the perversions back again to the physiological limits, and health is restored. To this beneficent law we owe the maintenance of the form and beauty of our race, in the presence of all that tends to spoil and degrade it. We cannot pass through the crowded streets and alleys of our cities without recognising proofs of this in the children's faces, in spite of all their squalor and misery; and, when we remember what this illustration in all its details reveals, we may well take heart, even where our work seems most hopeless. The effects of disease may be for a third or fourth generation, but the laws of health are for thousands. Bearing this in mind, I have often had occasion to remark in practice how little we can estimate the reparative powers, however able we may be to discover diseases. This is, perhaps, never more striking than in some chronic affections, which, having resisted all our efforts at cure, may have been abandoned in despair, or at length placed upon some indifferent treatment. Under these circum. stances, with what interest have most of us day by day watched the lessening deviations of disease, until the balance of health has been again all but restored, unstable though the equilibrium thus gained may, from the nature of the case, have been.

Therapeutics were at one time directed only by two ideas-of strength and of weakness. Sthenic and asthenic expressed in general terms the morbid conditions requiring treatment. Of the same import, but of older date, were the thoughts derived from the then current theory of phlogiston; and the terms phlogistic and anti-phlogistic still linger in medical treatises. From a better physiology we have learnt that perverted functions in disease, however exaggerated, are due to failure, and not to excess, of the vital powers.

Organic strength lies nowhere but in the vital circle of nutrition and function.

A rapid pulse and active delirium, like the increase of the animal heat, are signs of deficient balance-power-a power which we have been so slow to recognise in living organisms, that we have not yet an accepted expression for it. How different scems to us at the present day the value of the symptoms which were formerly considered indicative of strength.

For an increase of temperature we see but increased waste. Every degree of rise in the thermometer, indicales to us a corresponding decline in that nervous control which regulates the functions in health, and this decline is the more important, if it be true in complex organisms, as it is in simple machines, that this combination which limits the mere working forces is the highest and most characteristic. The terms "strength", and "weakness", are valueless, as expressive of conditions so complicated as those of disease. They are deduced for the most part from the feelings of the patient, and a few superficial phenomena. They are [empty] idols, impressive only by the extent of their emptiness. Surgical treatment was greatly advanced by the imaginary discovery of the sympathetic powder, which being placed upon the instrument inflicting the wound, the injured part, by time and rest, was allowed to recover under the simplest means. We need now to import into medicine a large part of the best surgical principles so deduced. The surgeon is contented to place a wounded part under the conditions of physical and physiological rest, and after attention to hygienic conditions, the res non naturales of our forefathers, to abide the result. This, no doubt, expresses the largest part of our treatment of common acute disease. We now know that we cannot directly control the morbid processes in pneumonia, pleurisy, or pericarditis; we know further that the means formerly considered essential to the cure of these disenses, tested by better clinical observations, were either useless or pernicious. That instead of favouring the plastic processes in inflammation, whereby the normal decline of the disease was promoted, the effused material was often more or less degraded and spoilt by the treatment employed, and remained in the affected parts, either as a foreign body, or in different degrees approaching thereto.

And this must always have been so, had we continued to regard these effusions as simply foreign products; but as soon as we perceived their physiological relations, and that they had a life like the tissues from which they sprang, they took a different aspect, and it became our duty, often without much interference, to stand by, and watch this course to the end. With an audience like the present, so capable of supplying the proper safeguards to these expressions, I am not likely to be misunderstood, as if the duties of the physician were of a negative kind. There is a sufficient sphere for our activity, in ways too numerous for me to mention :-in the relief of symptoms where the lesion may be left to its natural course :-in the treatment of the lesion itself, where we have means adopted to it ; and of these we have many :-in maintaining the health when the degeneration or lesion is incurable. Time would fail me if it were otherwise proper in this place to enumerate and enlarge upon the valuable applications of medicine. The discovery of disease ; - the alleviation of its symptoms - the obviating its inroads - the placing our patient under favourable conditions to bear it-the guarding him against what would be injurious-and the administration of remedies often in themselves effectual for its removal-are surely services of no unimportant kind.

There is probably no human work which daily confers greater good upon society than does ours; and when we consider that from the ranks of our profession the chief cultivators of modern sciences have sprung, whether we speak of botany, comparative anatomy, chemistry, physiology, biology, hygiene, or social science, we may feel some justifiable pride and be encouraged in spite of all failures to go on, assured that our future must be one of ever increasing usefulness and honour.

\section{THE RADICAL CURE OF HERNIA.}

EXTRACT FROM THE ADURESS IN SURGERY TO THE ANNUAL MEETING OF THE BENGAL BRANCH OF THE BRITISH MEDICAL ASSOCIATION.

\section{By J. FAYRER, M.D., F.R.S.E.}

IN the year 1862 I introduced into my wards a new and, as it seemed to me, more simple method of operating for the radical cure of hernia. I had previously practised that which is known as "Wuitzer's," or some of its modifications, such as that by Mr. Kedfern Davies, with some success; but owing to the complicated apparatus, and the tedium of the treatment, I was led to search for something that might prove as efficacious and, at the same time, more simple. I was indebted for the idea to Mr. Syme's plan of treating hernia; and that which I have adopted and now practise, and which I propose to explain, is a modification of Yrofessor Syme's method. I have, up to the end of 1866 , operated on 67 cases in the hospital, and have had several since; some of these cases are still under treatment, and those who are capable of being brought before the 
meeting I submit for your inspection, that you may have an opportunity of seeing the treatment in this stage. $I$ also hope to shew you certain cases that have been operated on sone time ago, and have thussatisfactorily solved the doubtful question whether the operation which at first is successful, can be permanent ill its good results.

The object of the operation is to close or so far contract the opening in the abdominal wall on its inner peritoneal aspect that the protrusion of the hernia shall be limited, or altogether prevented; and the mode in which this is accomplishea, is by procuring adhesion or contraction of the margin of the opening, whether at the internal ring in oblique inguinal hernia, or of the direct opening in the other forn. I believe that unless the operation eifect this purpose it is not likely to be successful; and as it is not possible to make certain of always accomplishing this end, a proportion of cases will fail. I find that, out of 67 cases operated on in the hospital, I I failed altogether, 9 were only relieved, that is, though not successful altogether, yet were so much improved that the hernia was controllable by a truss; one case only died; and in this instance, death was not due to peritonitis, but to erysipelas affecting the thorax; so that, although no doubt death was indirectly due to the operation, it was not the immediate result of it. Indeed, I know of no operation of importance attended with so little danger. Wound of the peritoneum does not necessarily involve dangerous consequences; more than once I have injured it by puncture, as proved by the free discharge of peritoneal fluid, but no ill result followed. In one case related in the Annals, this happened; the patient recovered and wrote to me from Ceylon some months after to say that he was perfectly well. The recoveries in nearly all the cases hare been rapid, and the proportion of success most gratifying; when we consider the importance of a favourable result, it is impossible not to feel satisfied that so simple a surgical proceeding should suffice so often to ensure it.

I have placed the instruments with which I operate on the table for your inspection, and you will see that they are very simple; a plug of wood, with two ligatures, a curved needle to pass the ligatures through the abdominal wall; a second small piece of wood to knot the ligatures over, completes the apparatus. The method of performing the operation is simple, but it requires some care and confidence for its effective com. pletion. The fore-finger of the left hand oiled, is inserted into the inguinal canal, and the scrotum invaginated is pushed before it up to the internal ring with firm and decided pressure. One ligature, strong and well waxed, is then threaded in the needle, the point of which is insinuated along the palmar aspect of the fiuger on its radial side, until it has reached the extreme apex of the invagination; it is then forced through the abdominal parietes, and appears on a line with the anterior superior spine of the ilium; about $1 \frac{1}{y}$ or 2 inches internal to. The needle is then unthreaded and withdrawn, to be threaded with the second ligature, and again introduced, this time on the other side of the finger, to be pushed through the abdominal wall as before; this time transfixing a short distance from the point where it first pierced, but emerging through the same opening in the integument.

The needle is again unthreaded and withdrawn. The plug is now pulled into the canal, the apex being firmly tied against the apex of the invagination, and the threads firmly knotted over the small piece of wood. The operation is thus completed.

The plug is left in situ for three or four days or more, until pus appears to flow freely from beside the ligatures. These are then cut, and the plug withdrawn. The discharge is gently pressed out, a pad and spica bandage are applied, and the patient is kept in bed and cautioned not to strain at stool for some days. As soon as the wounds have cicatrised, a truss may be applied, which should be worn for some months, especially when any exertion is made; it may gradually be left off when the tissues have become firmly consolidated. The time occupied in treatment varies from a month to six weeks in ordinary cases; if there be much suppuration, and that have burrowed among the abdominal muscles, there may be delay, and counter-openings may be necessary; but such cases are the exception. The only one was that of a native who was attacked with erysipelas and died of pyrmia, the result of cellulitis. During the period of the insertion of the plug, the bowels generally remain confined, and indeed for several days after its removal; should they act, the patient must be warned against efforts at straining.

1 find, by referring to the records of my wards, that $I$ have, up to the end of 1867 , operated sixty-seven times. In 1862 , I had fifteen cases, of which ten succeeded, one was relieved, and four failed. In 1863 , there wcre eight cases, of which five were successful, two were only rclieved, and one failed. In 1864 , I had eight cases, of which six were successful, two relieved. In 1865 , I operated in fourteen cases, of which ten werc successful, three relieved, one failed. In 1866, there were seven cases, five successful, two failed. In 1867 , I had fifteen cases, of which ten were successful, one was relieved, three failed, and one
died.
Ram Coomas Doss was admitted on the 27th February, i867, with inguinal hernia of left side; he was operated on, 5th March, 1867, and died of erysipelas, on the 26th March 186\%. Extensive suppuration was set up between the muscles. Erysipelas took place in the chest, the cellular tissue sloughed, and free incisions were made to expose the sloughy tissues. After death, there was found consolidation of the two lower lobes of the right lung, and one large pyæmic patch of the upper lobe. There were no cardiac coagula. There was thus a total of sixty-seven cases, of which forty-six were apparently successful; nine were relieved; eleven failed altogether, and one died.

Before discharging any of those returned as cured, they were submitted to the severest tests, lifting weights, climbing up a pole, jumping, running up and down-stairs without a truss; and unless they were able to bear this test, they were not considered as cured. In many of these I fear the hernia may have returned afterwards. But I have seen some after a long interval, and am happy to say there can be no doubt that in these cases the improvement is permanent.

I have placed on the table a specimen illustrative of the mode in which the occlusion is effected; it was the case of a French sailor, who had been operated on some months before he met with an accident, which caused his death. You will see that the internal ring is perfectly closed. I have also brought into the room several patients who are recovering from the operation, and so far they promise to do well. I have also some persons who were operated on at different periods of time past, and you will be able to judge by them how far we may, in favourable cases, hope to succeed. I would here repeat what I have often before stated, that I regard the operation as one of a somewhat uncertain character as to its results, but offering a sufficient prospect of success to warrant the surgeon, and justify the patient, in attempting it.

\section{WHAT ARE DISEASES ?}

\author{
By SAMUEL WILKS, M.D., F.R.C.P.,
} Physician to and Lecturer on Medicine at Guy's Hospital.

UNDER the above name, Dr. Handfield Jones has opened up the most vital question, I believe, in the whole domain of medicine, since it shews that the very first principles of treatment are not yet settled. The writer has argued the subject in his usual judicious manner, and thus the truths which he asserts must carry conviction to all readers; at the same time, they are evidently the expressions of facts seen on one side, and are intended for those who have not thought of disease from the author's point of view. I believe, however, that there is much to be said on the other side of the question; and I myself think that, at the present day, this is the more important, seeing that the tendency of the medical mind is in the direction which Dr. H. Jones has taken.

He shews in his paper, in opposition to antiquated views, that which we style disease is nothing which the mind can grasp in the form of a distinct entity added to the human frame, but rather a deranged condition of the animal machinery, and therefore, that our art must be directed to correct such derangement rather than to be used in attempt. ing to fight some imaginary or unknown phantom, which we call 'the disease.' In fact we must not treat something which we call disease, but we must treat the patient. It may not be that the author of this paper maintains this doctrine in all its exclusiveness, but the tendency of his remarks is certainly to support the idea; he may indeed strongly maintain it, and if so, I have no doubt the majority of the profession is with him. It is a doctrine, long inculcated at my own medical school, and one which I myself at one time enforced upon students. Having had reason, however, now for many years to very much modify my opinions, I could not refrain from expressing these in a journal which has disseminated the remarks of so distinguished a physician as Dr. H. Jones. The principal object I have in doing so, however, is a practical one; since the treatment of our patients, according to the opinion we hold, must often be at complete variance, and thus one method must be essentially errnneous; of course, I should fear no harm in the discriminating hands of the writer, but with less judicious practitioners, a false theory leads to an utter disregard of diagnosis, of the value of remedies, and to a treatment of disease based simply on popular and preconceived notions.

The question is really a most fundamental and vital one. Is there, or is there not, a sufficient resemblance in certain morbid states occurring in different individuals, and which we designate by a name, to demand a similarity of treatment? The question is to be answered by expe. rience alone; but for myself I believe that some general principles and particular remedies may be found for the treatment of disease, not overlooking of course the individual peculiarities of the patient. I find that many in our profession, whilst acknowledging their difficulty in treating 